\title{
Active Modified Atmospheric Packaging of Mango (cv. Dushari): An Experiment with Potassium Permanganate and Salicylic Acid
}

\author{
Ranjeet Singh ${ }^{1^{*}}$ and S.K. Giri ${ }^{2}$ \\ ${ }^{1}$ AS\&EC Division, ICAR-Central Institute of Post-harvest Engineering \& Technology, \\ Ludhiana Punjab-141 004, India \\ ${ }^{2}$ APPD Division, ICAR-Central Institute of Agricultural Engineering, Nabi-Bagh, Berasia \\ Road, Bhopal 462 038, India \\ *Corresponding author
}

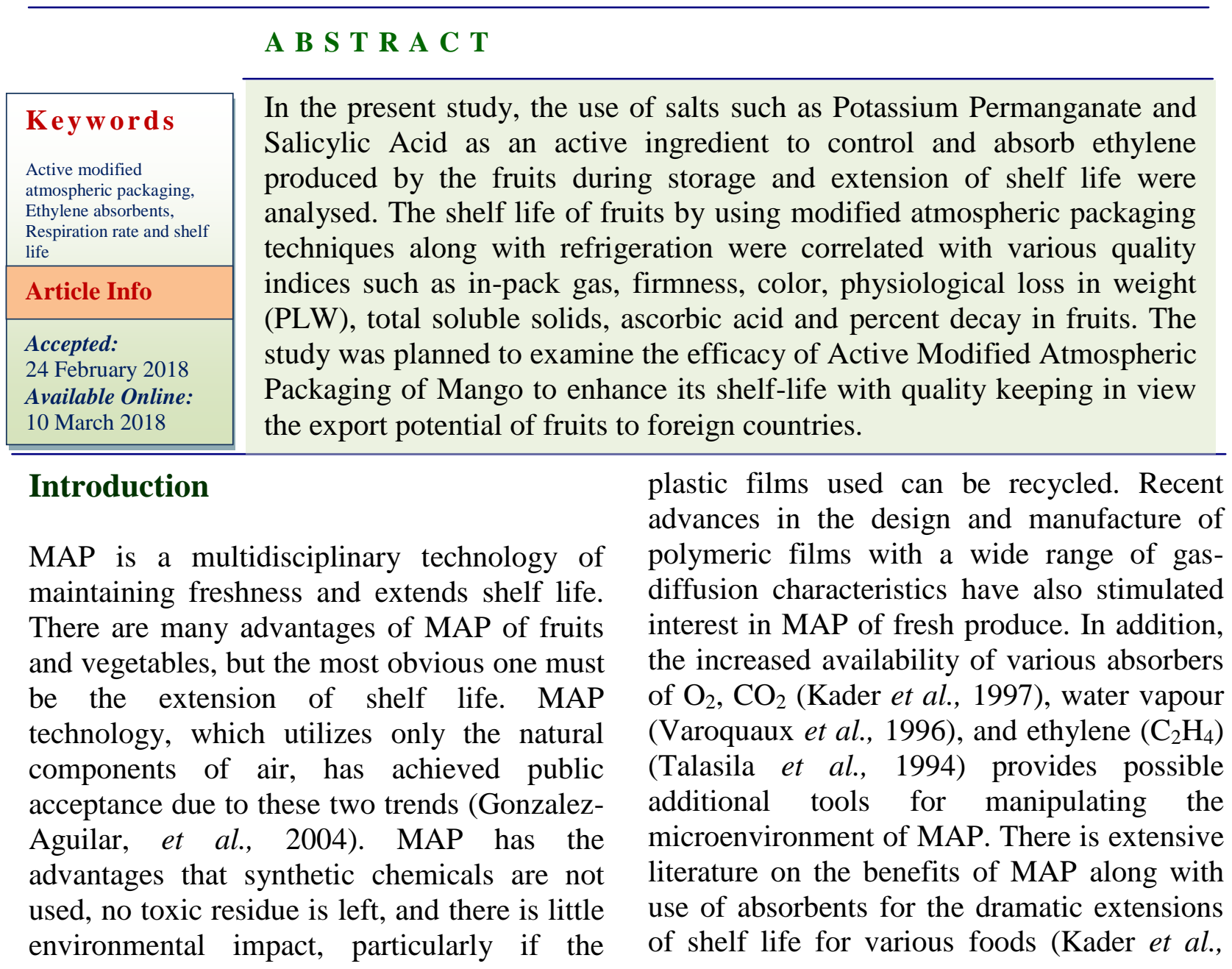


1997). Ethylene is the natural product of plant metabolism and is produced by all tissues of higher plants and by some microorganisms. It is the simplest of all the organic compounds and considerably affecting the physiological processes of plants and the commodity after harvest (Aharoni et al., 1987). Exposure of climacteric fruits to ethylene advanced the onset of an irreversible rise in respiration rate and rapid ripening. Various packages can delay the onset of climacteric and prolong shelf life of fruits by reducing ethylene production and sensitivity (Fonseca et al., 2000). Keeping in view, the present study was designed to evaluate the efficacy of ethylene absorbents Potassium Permanganate and Salicylic Acid to extend shelf-life fruits for export market.

\section{Materials and Methods}

\section{Fruit material}

The fruit Mango (cv. Dushari) of uniform size, without defects or diseases were handpicked/harvested at their commercial maturity from farm.

They were visually inspected for freedom from defects and blemishes and non-uniform, damaged, poor quality was removed. Fruits were also exposed to UV light for surface disinfestations and given pre-hot air treatment at $49^{\circ} \mathrm{C}$ for $10 \mathrm{~min}$.

\section{Design of packaging system}

Active modified atmosphere packages were designed based on the respiration rates of the products, film parameters and environment factors. The respiration rate of mango fruits was determined as per the method adopted by Singh et al., (2013). Based on design calculations using PACK-in-MAP software, perforated LDPE film $(75 \mu \mathrm{m})$ was selected for bulk packaging $(10 \mathrm{~kg})$ of fruits.

\section{Active packaging with modified atmosphere} storage

For active packaging, experiments was carried out with treatments of MAP with Potassium permanganate as ethylene absorbent (refrigerated), MAP with Potassium permanganate (PP)+ salicylic acid (SA) as ethylene absorbent (refrigerated). The sachets were prepared @ $9 \mathrm{~g}$ silica crystals per kg of packed fruits by filling pure potassium permanganate imbedded in silica crystals in woven polyester cloth with high permeability (Singh et al., 2014a). The fruits were dipped in Salicylic acid @ 0.15g/lit, before packaging experiments. The treatment bags were immediately shifted and were stored at storage temperature $\left(14 \pm 1^{\circ} \mathrm{C}\right)$ and $95 \%$ relative humidity $(\mathrm{RH})$ in environmental control chamber. The experiments were also done for control storage in refrigerated conditions (CR) at defined temperature.

Measurement of in-pack gaseous composition and respiration rate

The in-pack gaseous composition of $\mathrm{O}_{2}$ and $\mathrm{CO}_{2}$ were analyzed in all MA packages during storage using a portable headspace gas analyzer (Model GS3M, Systech Instruments Ltd. UK). The respiration rate (RR) of fruits in term of $\mathrm{CO}_{2}$ librated $(\mathrm{ml} / \mathrm{kg}-\mathrm{h})$ were determined in all treatment packages during storage as per the method adopted by Singh et al., (2014b).

\section{Evaluation of shelf life quality}

Shelf-life of fruit was assessed by various quality parameters such as in-pack gas, firmness, color, physiological loss in weight (PLW), total soluble solids, ascorbic acid and decay. Fruit firmness was analyzed by measuring the maximum compression force using Texture Analyzer Stable Micro Systems, Model TA.XT. plus. The Data were recorded 
in triplicate and the mean values were expressed as kgf. Color development of fruit (skin) was measured at harvesting and during storage using a colorimeter (chroma-meter) (Miniscan XE plus, Hunter associates, USA). PLW was measured by using hand held refractometer. The color of the fruit was measured on every $7^{\text {th }}$ days of storage, the ' $L$ ', and ' $a$ ' values were recorded as an average of 15 measurements. Physiological loss in weight was determined by weighing all samples with a laboratory level weighing scale (Model CT$35 \mathrm{~K} 2$, Contech Instruments Ltd. India) having least count $\pm 2 \mathrm{~g}$ at the beginning and end of the storage period.

The difference between the two values was considered as weight loss and expressed in percentage. Ascorbic acid was determined using the 2,6 dichlorophenolindophenol method (AOAC 1990) and expressed in $\mathrm{mg}$ per $100 \mathrm{~g}$ of the initial fruit mass. Measurements were taken at the beginning and on every $7^{\text {th }}$ days of storage. Measurements of the ascorbic acid were carried out in all packaging treatment, as an average of 3 measurements. Percentage of decay was obtained from the number of fruit that showed signs of decay over the initial number of fruit. The cumulative decay during storage period was recorded and expressed as a percentage. The percent samples excluding decay after end of the storage period represent marketability.

\section{Statistical analysis}

The experimental data were analyzed using GLM procedure available in SAS (SAS Institute India Pvt. Ltd.). Completely Randomized Design (CRD) was used in the experiment. The significance of different methods, their pair wise comparison and estimations of coefficients were carried out. The pair wise comparison was performed using Tukey's Studentized Range (HSD) Test.

\section{Results and Discussion}

\section{In-pack gas composition}

In pack gaseous composition in terms of $\mathrm{O}_{2}$ depletion and $\mathrm{CO}_{2}$ evolution during the storage of matured mango fruits (cv. Dusheri) in different packaging system at $14 \pm 1^{\circ} \mathrm{C}$ temperature is showed in plate 1 . It was observed that, by the end of day 7 , a rapid decline in $\mathrm{O}_{2}$ and subsequently rapid increase in $\mathrm{CO}_{2}$ evolution set-in both the MAP (PP) and MAP $(\mathrm{PP}+\mathrm{SA})$ treatments and then maintained steady state thereafter.

\section{Physiological loss in weight (\%)}

Among all the packaging treatments, the control sample (CR) showed significant increase in physiological weight loss. However, the PLW was very minimal in both the MAP (PP) and MAP (PP+SA) refrigerated samples during and by the end of the storage period with no visible formation of water drips and fogging in the packages. The use of imbedded silica crystals sachets under active packaging acted as anti-fogging and reduced water drips and moisture loss and significantly reduces PLW (Plate 2).

\section{Fruit firmness}

The firmness of fresh fruits was $26.17 \mathrm{kgf}$. A continuous decline in fruit firmness was observed in all the packaging treatments by the passage of storage period. Fruit firmness was significantly protected by both the MAP (PP) and MAP (SA) samples by the end of day 49, respectively. However, a steep and significant decline in fruit firmness was observed for the control (CR) sample by the end of day 21 respectively (Plate 3 ). In MAP $(\mathrm{PP}+\mathrm{SA})$ refrigerated, fruit firmness finally settled at $2.11 \mathrm{kgf}$, respectively by the end of storage period of 42 and 5 days at room temperature. 
Plate.1 In-pack gaseous composition

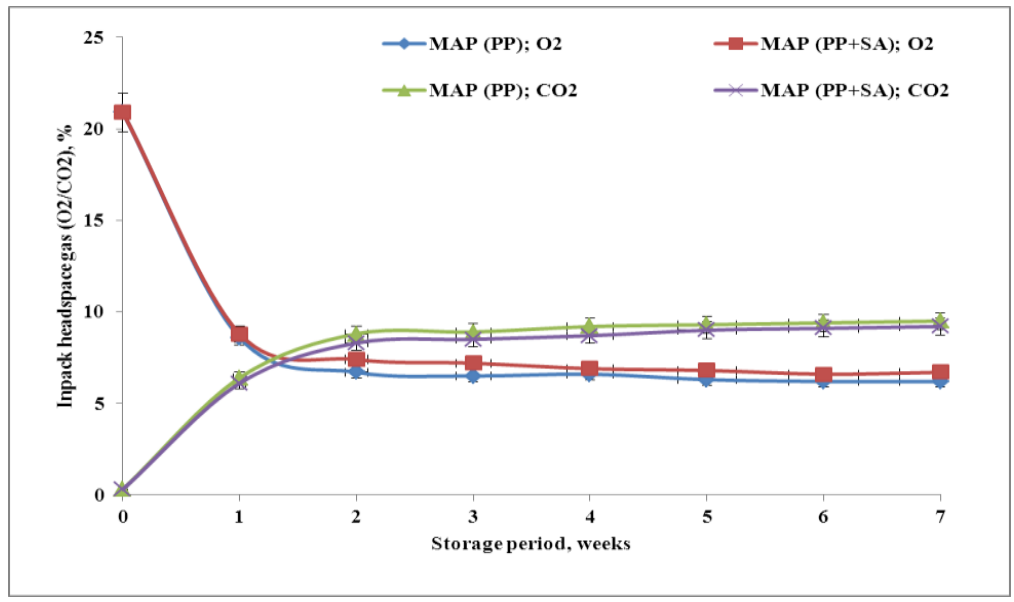

Plate.2 Physiological loss in weight (PLW, \%)

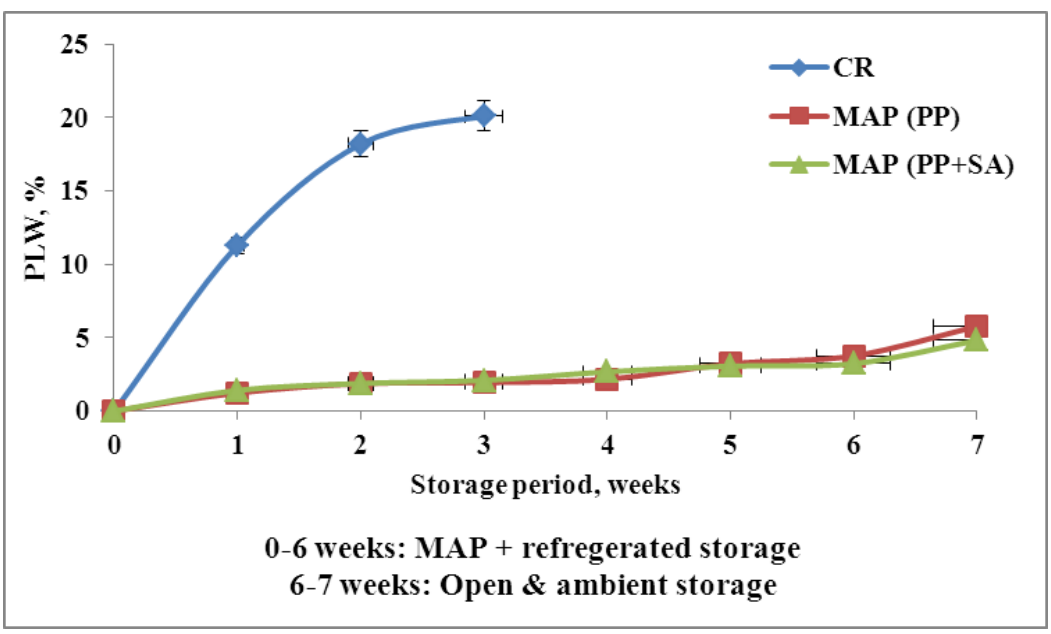

Plate.3 Fruit firmness during storage

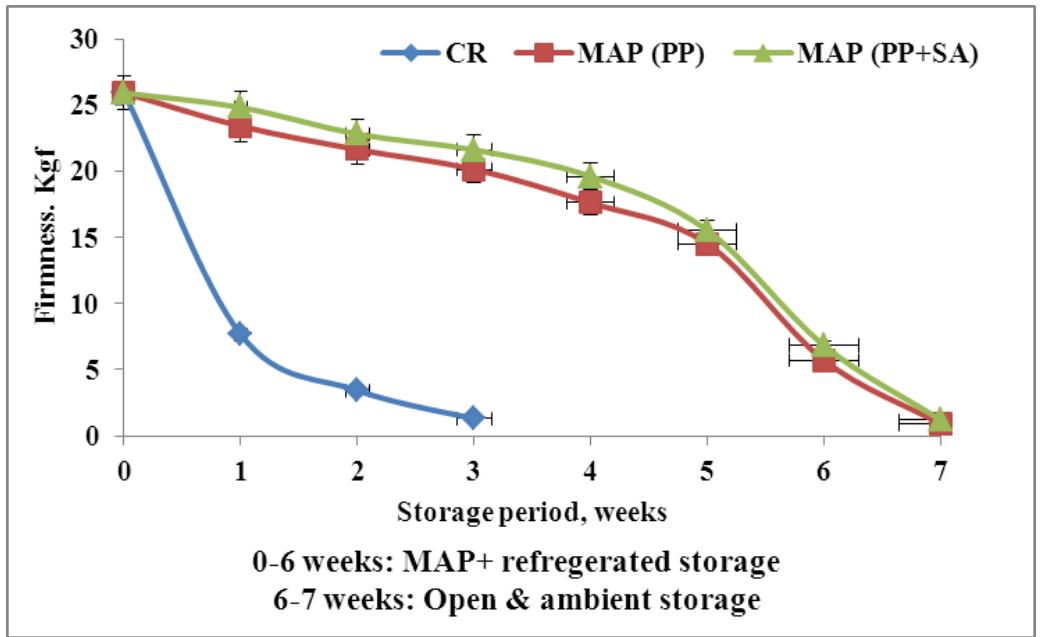


Plate.4 Total soluble solid content

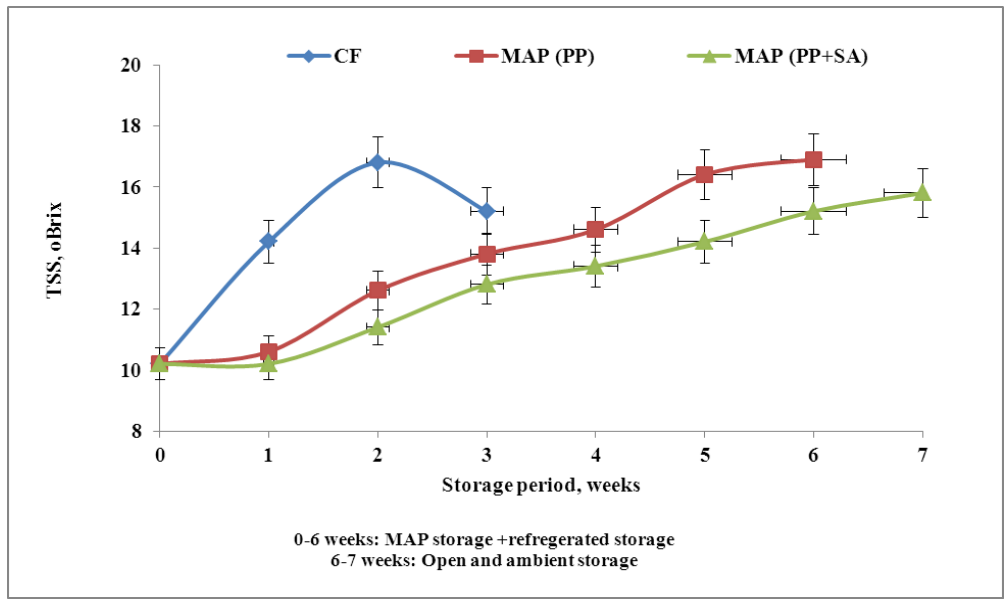

Plate.5 Hunter 'a' value of fruits during storage

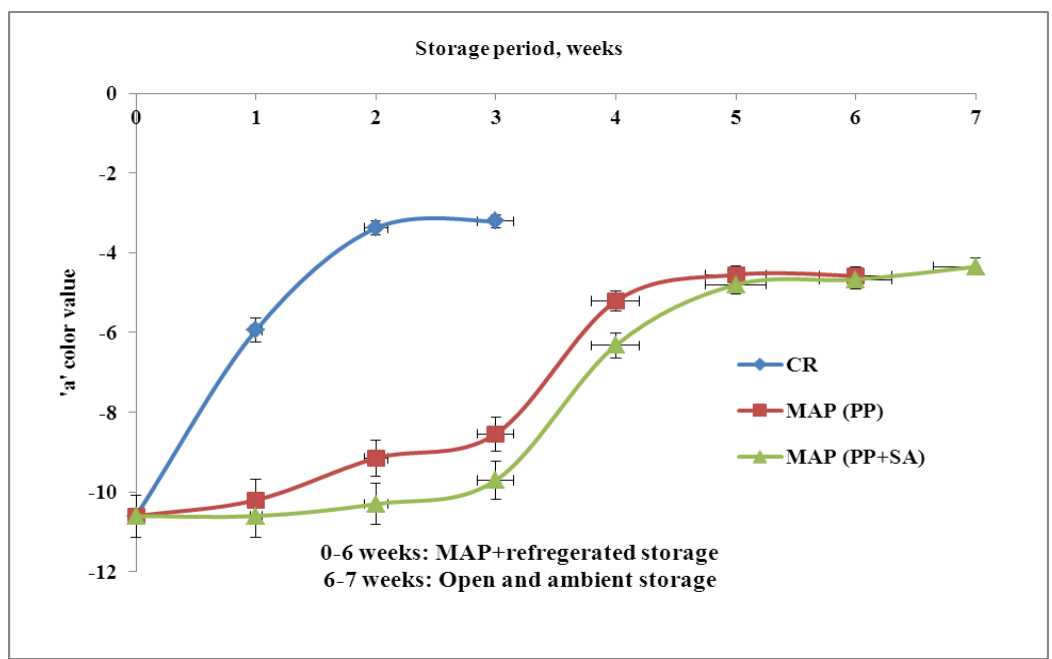

Plate.1 MAP (PP+SA) packed fully ripe mango after 6 weeks in refrigerated MA storage (a) and addition 5 days storage at room temperature (b)

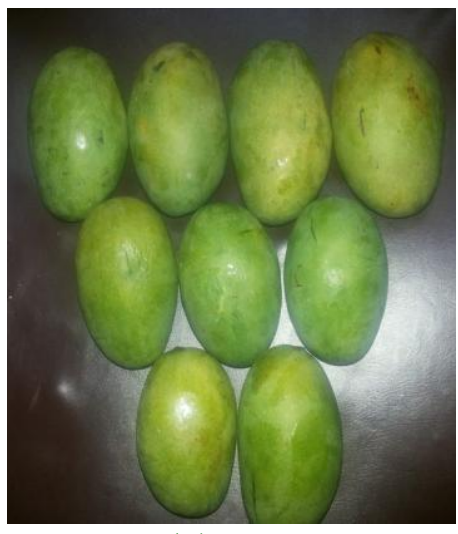

(a)

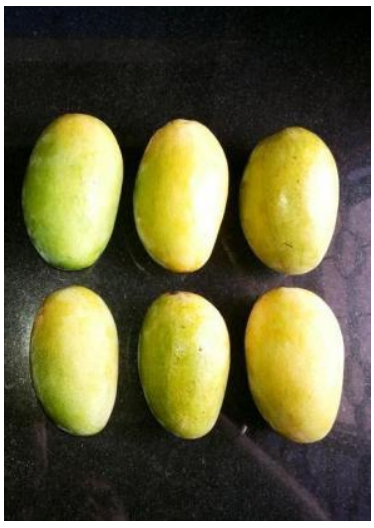

(b) 
Table.1 Comparative table of quality indices of mango

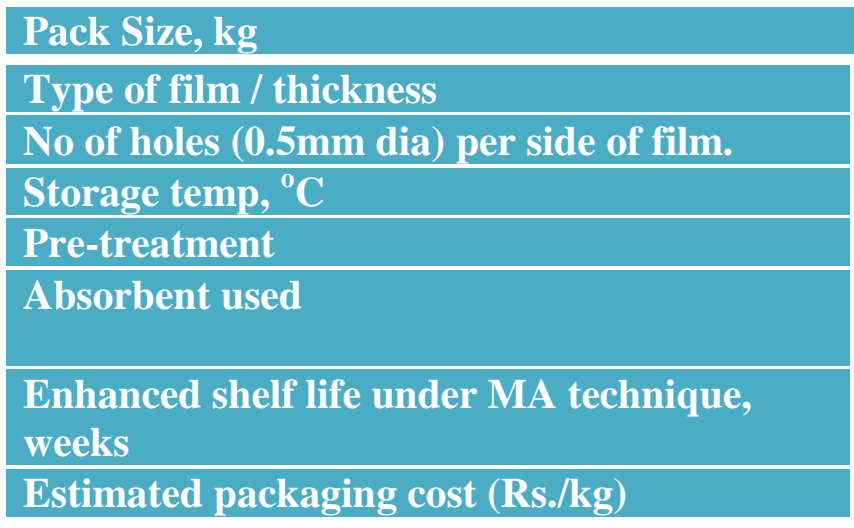

\section{Total soluble solids (TSS)}

An increasing trend in total soluble solids (TSS) content was observed in all the MAP and control samples. The TSS content was found maximum in control (refrigerated sample) by the end of day 21 followed by MAP (PP) and MAP (PP +SA) refrigerated samples (Plate 4).

\section{Color 'a' value}

The green color of both the MAP (PP) and MAP (SA) treatments were well protected by the packaging treatments during storage up to day 42. After 21 days sharp change in green color depicted by hunter ' $a$ ' value was observed in both the MAP (PP) and MAP (SA) packages. After wards steady state conditions were observed (Plate 5).

\section{Fruit decay (\%)}

The major sign of decay in mango fruit in all packaging treatments are one or in combinations of the following: skin abrasions, low temperature injury, soft nose and pathological disorders like Anthracnose. The decay was largely exhibit in control (CR) fruits and significantly differs with MAP (PP) and MAP (PP+SA). Package treatment CR had maximum decay of more than $15 \%$ by the end of storage life (day 21). MAP (PP)

\begin{tabular}{|c|}
\hline LDPE $/ 75 \mu$ \\
10 \\
14 \\
\hline Hot air $49-50^{\circ} \mathrm{C}$ for 10 min \\
\hline $\begin{array}{c}\text { Potassium permanganate and salicylic acid } \\
\text { as ethylene absorbents }\end{array}$ \\
\hline 5 \\
\hline 5
\end{tabular}

and MAP $(\mathrm{PP}+\mathrm{SA})$ treatment had minimum decay value of $3.9 \%$ and $2.10 \%$ by day 35 and day 49 , respectively. The fruit decay in active packaging was significantly reduced by the use of Ethylene absorbents (PP+SA) sachets during storage period.

\section{Shelf life}

Modified atmospheric packed mango in $75 \mu \mathrm{m}$ thick LDPE package, with ethylene absorbents $(\mathrm{PP}+\mathrm{SA})$ was found to have a shelf-life of 42 days at refrigerated conditions plus 5 days at ambient after opening of MA packages. Into the shelf life was enhanced upto 6 weeks +5 days. However, the control fruits had a shelf-life of 12 days. The comparative table of quality indices were given in Table 1.

The use of ethylene absorbent/ moisture absorbent along with modified atmospheric packaging as a postharvest tool may be adapted into the supply chain activities of the above produces to enhance storage life and ensure quality during distribution to local/super markets and to maximize customer value.

\section{Acknowledgement}

The authors are highly grateful to the Director, ICAR-CIPHET, Ludhiana and 
ICAR-CIAE, Bhopal for the support and encouragement to carry out the work.

\section{References}

Aharoni, N., Philosoph-Hadas, S and BarkaiGolnn, R. (1987) Modified atmosphere to delay senescence and decay of broccoli. Proceedings of $4^{\text {th }}$ National Controlled Atmospheres Research Conference July 1985. North Carolina, 169-177

Fonseca, S.C., Oliveira, F.A.R., Lino, I.B.M., Brecht, J.K, and Chau, K.V. 2000. Modeling $\mathrm{O}_{2}$ and $\mathrm{CO}_{2}$ exchange for development of perforation mediated modified atmosphere packaging. $J$ of Food Engng, 43 (1), 9-15

Gonzalez-Aguilar, G., Ayala-Zavala, J.F, Ruiz-Cruz, S., Acedo-Felix, E and Diaz-Cinco, M.E. 2004. Effect of temperature and modified atmosphere packaging on overall quality of freshcut bell peppers. Lebensm.-Wiss. u.Technol., 37: 817-826

Kader, A. A. 1997. A summary of CA requirements and recommendations for fruits other than apples and pears. In A. A. Kader (Ed.), Proceedings of the 7th international controlled atmosphere research conference, 3: 1-34, Davis, CA, USA

Singh, R. and Giri, S. K. 2014b. Respiration rate model for mature green capsicum (Capsicum annum L.) under closed aerobic atmospheric conditions, Croatian J of Food Sci and Technol., 6 (2): 110-115.

Singh, R., Giri, S. K. and Kotwaliwale, N. 2014a. Shelf-life enhancement of green bell pepper (Capsicum annuum L.) under active modified atmosphere storage, Food Pac \& Shelf life., 1 (2): 101-112

Singh, R., Giri, S. K. and Kulkarni, S. D. 2013. Respiratory behaviour of mature light green Guava Psidium guajava L.) under closed system, Sci J of Agric. Engng., 1: 23-29

Talasila, P.C., Cameron, A.C and Joles, D.W. 1994. Frequency distribution of steadystate oxygen partial pressures in modified atmosphere packages of cut broccoli. J of the Am. Soc. for Horti. Sci, 119: 556-562

Varoquaux, P., Mazollier, J and Albagnac, G. 1996. The influence of raw material characteristics on the storage life of fresh-cut butterhead lettuce. Post harv. Bio. \& Technol, 9: 127-139

\section{How to cite this article:}

Ranjeet Singh and Giri, S.K. 2018. Active Modified Atmospheric Packaging of Mango (cv. Dushari): An Experiment with Potassium Permanganate and Salicylic Acid. Int.J.Curr.Microbiol.App.Sci. 7(03): 2790-2796. doi: https://doi.org/10.20546/ijcmas.2018.703.321 